\title{
A RESEARCH ON THE DIGITAL HYDRAULIC POSITIONING BY MULTI-CYLINDER SYSTEMS
}

\author{
Takayuki Torikai*, Toshio Takenaka** \\ Ryuichiro Yamane*, Hiroshi Katakura*** \\ *Tokyo Institute of Technology \\ Tokyo, Japan \\ ** Musashi Institute of Technology \\ Tokyo, Japan \\ ***Tokyo Engineering University \\ Tokyo, Japan
}

The dynamic characteristics of the hydraulic system made of the four cylinders, all of which were connected tandem and able to move on a linear guide rail, was investigated in this research.

In this system, four directional control valves controlled the ON-OFF motions of the cylinders of the same number respectively and separately. A valve was connected to a cylinder by a pair of flexible pipes. One micro-computer drove all the valves by its $O N-O F F$ electric signals. One end of the system was fixed to the rail and the other was free. Displacements of the free end were the outputs of the system. The strokes of the cylinders were chosen as $1 \mathrm{~cm}, 2 \mathrm{~cm}, 4 \mathrm{~cm}$ and $8 \mathrm{~cm}$ from the free end, for the free end of the system could stop anywhere in the 16 positions from $0 \mathrm{~cm}$ to $15 \mathrm{~cm}$ at $1 \mathrm{~cm}$ intervals depending on the output signals from the micro-computer.

This paper shows some of the results obtained from the above research.

\section{KEYYORDS}

\footnotetext{
Digital control, Hydraulic system, Micro-computer, Cylinder, Positional control
}

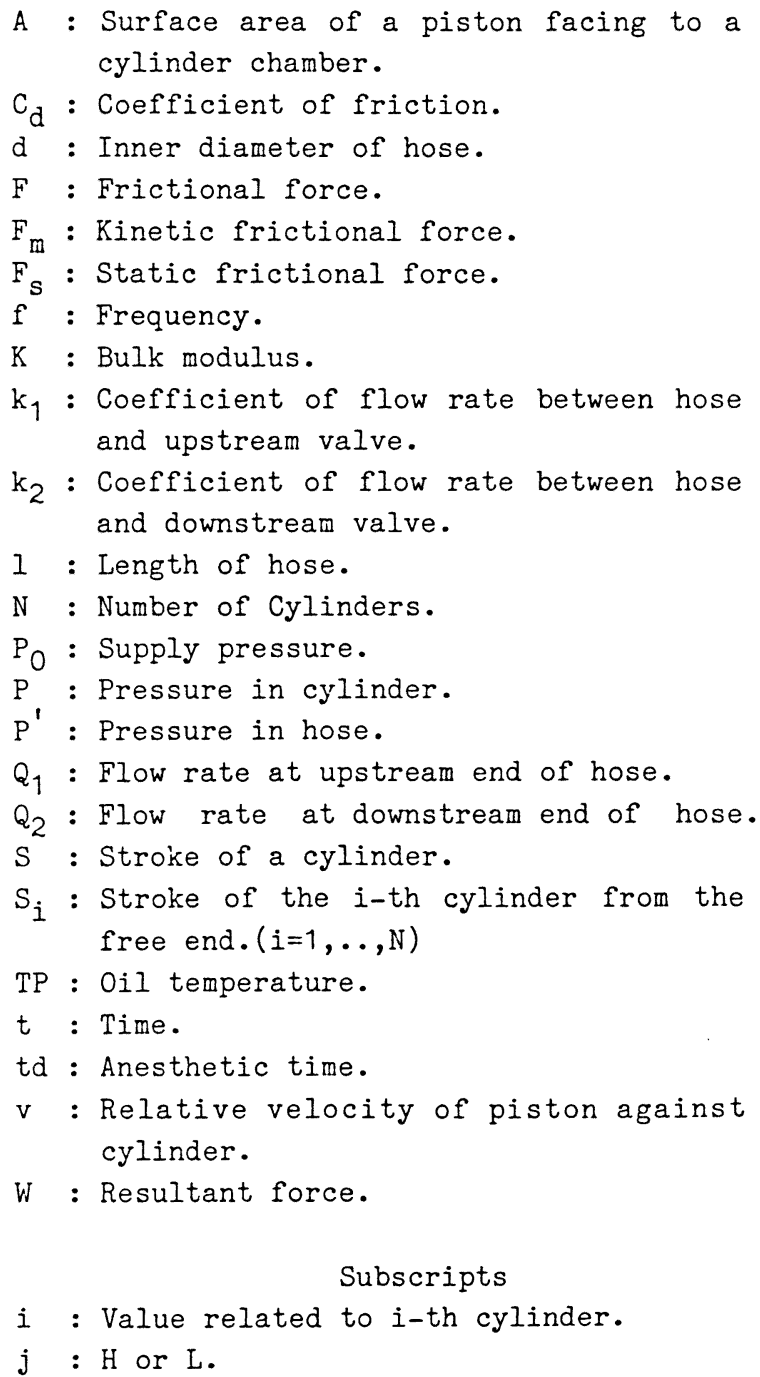


$\mathrm{H}$ : Value related to higher pressure side. L : Value related to lower pressure side.

\section{INTRODUCTION}

Recently, applications of microcomputers to various machines have been considered, because their price have been reducing quickly and their functions have become much higher than ever. To some hydraulic systems, micro-computers were applied and their applications to the other hydraulic systems are widely studied now.

This paper presents the digital control of one of those systems, the digital hydraulic positioning by multicylinder system with directional control valves driven by a micro-computer. It has multi-tandem-cylinders which are digitally controlled by pressure signal transmitting through hydraulic hoses.

The purpose of this research is to develop a new hydraulic system to which a micro-computer is applied. In the same field of researches, some results have been reported by Nakamura and Tanaka [1]. At the case of the system of Nakamura and Tanaka, the digitalizations of pressure and flow rate were tried, but, in our system, the displacement of actuators are controlled directly by the digital signals from the micro-computer. This method is advantageous for static-positioning, at least because the increase in the number of output bits of a micro-computer in this system makes the static-positioning of the system more precise while the system is rather complicated.

\section{MODELING OF HYDRAULIC SYSTEM}

\section{Summary of modeling}

The schematic model of digitally controlled hydraulic system is shown in Fig. 1. The proportion of each cylinder stroke is $1: 2: 4: 8: \ldots: 2^{\mathrm{N}-1}$ when there are $N$ cylinders in this system. One end of the system is fixed, and the other is free, representing the output displacement of the system. The $i-t h$ cylinder has the stroke $\mathrm{S}_{i}=\mathrm{S}_{1} 2^{i-1}$. So output displacements is from 0 to $S_{1}\left(2^{\mathrm{N}}-1\right)$ with $2^{\mathrm{N}}$ steps at $\mathrm{S}_{1}$ interval.

\section{Fundamental equations of model}

We consider about i-th cylinder when the fixed end port is connected to higher pressure side and the free end port to lower pressure side. At first we form the equation about the pipes of higher pressure side $(H)$ and lower pressure side (L) which are connected to the directional control valve and the cylinder ( $\mathrm{H}$ or $\mathrm{L}$ is $j$ ). The oil flow rate of inlet or outlet pipe is $Q_{1 j i}$ or $Q_{2 j i}$. Considering the expansion of the pipe, the increase in pipe diameter $d$ in time interval $t$ is

$$
\begin{aligned}
\left\{\pi\left(d_{11}+\delta d_{j i}\right)^{2}\right. & \left./ 4-\pi d_{j i}{ }^{2} / 4\right\} 1_{j i} \\
& =\left(Q_{1 j i}-Q_{2 j i}\right) \delta t
\end{aligned}
$$

The relation between the volume of hose $V_{j i}$ and the pressure in the hose $P_{j i}^{\prime}$ is,

$$
\delta \mathrm{V}_{j i} / \mathrm{V}_{j i}=\delta \mathrm{P}_{j i}, / \mathrm{K}_{j i}
$$

where $K_{j i}$ is the bulk modulus of the hose filled with the oil. From Eqs. (1) and (2), we have

$$
\left(\pi d_{j i}{ }^{2} 1_{j i} / 4 K_{j i}\right) d P_{j i} / d t=Q_{1 j i}-Q_{2 j i}
$$

Then we consider balance of forces of the piston in a cylinder. The resultant force $W_{i}$ acting to the piston is

$$
P_{H i} A_{H i}-P_{L i} A_{L i}=W_{i}
$$

where $\mathrm{P}_{\mathrm{Hi}}$ is the pressure in the cylinder and $A_{H i}$ is the sectional area of the higher pressure side. $P_{L i}$ is the pressure and $A_{L i}$ is the sectional area of the lower side.

$W_{i}$ can be represented by oil viscosity and frictional force of the piston as

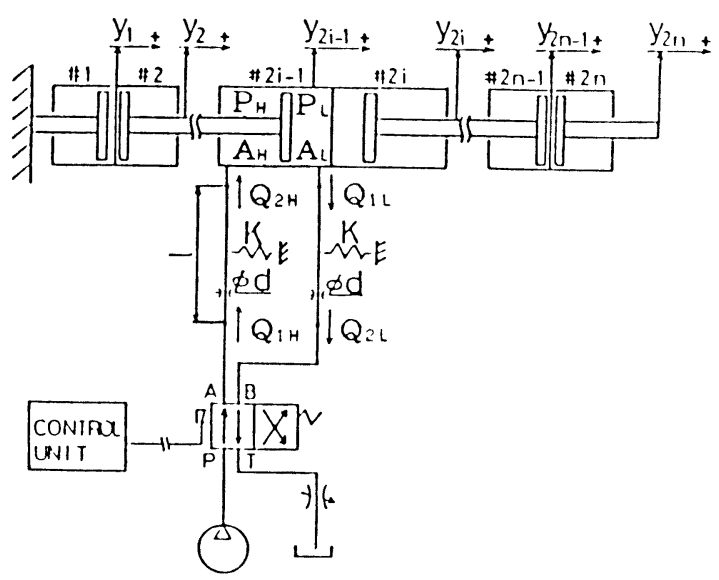

Fig. 1 Model for analysis 


\section{Anesthetic time}

A certain time, during which the piston is stationary before starting even though the directional control valve has been opened as shown in Fig. 2, is called "the anesthetic time". During this time there is no inflow and outflow in the cylinder.

The orifice is formed in the directional control valve and the flow control valve. So the flow rates at the hose ends on the higher presser side with the supply pressure $\mathrm{P}_{0}$ are

$$
\begin{aligned}
& Q_{1 H i}=K_{1 H i}\left(P_{B}-P_{H i}\right)^{1 / 2} \\
& Q_{2 H i}=0
\end{aligned}
$$

The flow rates at lower pressure side are

$$
\begin{aligned}
& Q_{1 L i}=0 \\
& Q_{2 L i}=k_{2 L i} P_{L i}, 1 / 2
\end{aligned}
$$

From Eq. (3),

$$
\begin{aligned}
& T_{H i} d P_{H i}, / d t=k_{1 H i}\left(P_{B}-P_{H i}\right)^{1 / 2} \\
& T_{L i} d P_{L i}, / d t=k_{21} P_{L i}, 1 / 2
\end{aligned}
$$

where

$$
T_{j i}=\pi d_{j i}^{2} 1_{i i} / 4 K_{j i}
$$

The pressures in the cylinder at time $t$ are

$$
\begin{aligned}
P_{H i} & (t) \\
= & P_{B}-\left\{k_{1 H i} t / 2 T_{j i}-\left(P_{B}-P_{H i},(0)\right)^{1 / 2}\right\}^{2} \\
P_{L i} & (t) \\
= & \left\{k_{2 L i} t / 2 T_{j i}-P_{L i},(0)^{1 / 2}\right\}^{2}
\end{aligned}
$$

where $P_{j i}^{\prime}(0)$ is the pressure when the directional control valve is just being opened.

During this time there is no inflow and outflow between the cylinder and the hose. Then

$$
\begin{aligned}
& P_{H_{i}}{ }^{\prime}=P_{H i} \\
& P_{L^{\prime}}{ }^{\prime}=P_{L_{i}}
\end{aligned}
$$

Since $d v_{i} / d t=v_{i}=0$ during this time, the frictional force $F_{i}$ is the static one $\mathrm{Fs}_{i}$. From Eq. (4)

$$
P_{H i}(t d) A_{H i}-P_{L i}(t d) A_{L l}=F s_{i}
$$

$$
\begin{aligned}
& P_{H i}(0)=P_{H i},(0)=0 \\
& P_{L i}(0)=0
\end{aligned}
$$

From Eqs. (10), (11) and (12), the anesthetic time is represented as

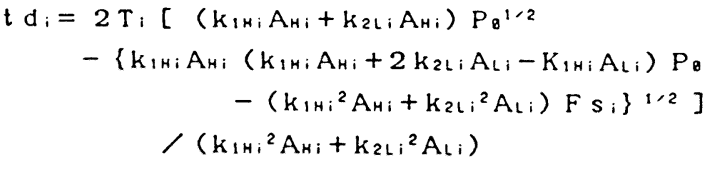

where

$$
T_{H i}=T_{L i}
$$

\section{Moving velocity}

The kinetic friction $\mathrm{Fm}_{i}$ is assumed constant, when the piston is moving at constant velocity. Then $P_{j i}$ is constant from Eqs. (4) and (5). Then

$$
P_{H} ; A_{H i}-P_{L i} A_{L i}=C d_{i} V_{i}+F m_{i}
$$

$Q_{2 \mathrm{Hi}}$ and $\mathrm{Q}_{2 \mathrm{Li}}$ are constant, and

$$
d P_{j i}, / d t=0
$$

The flow rates at the pipe ends on the higher pressure side are

$$
\begin{aligned}
& Q_{1 H i}=k_{1 H i}\left(P_{B}-P_{H i},\right)^{1 / 2} \\
& Q_{2 H i}=k_{1 L i}\left(P_{H i},-P_{H i}\right)^{1 / 2}=V_{i} A_{H i}
\end{aligned}
$$

The flow rates on the lower side are

$$
\begin{aligned}
& Q_{1 L i}=k_{2 H i}\left(P_{B}-P_{L i},\right)^{1 / 2}=V_{i} A_{L i} \\
& Q_{2 L i}=k_{2 L i} P_{L i}, 1 / 2
\end{aligned}
$$

where

$$
Q_{1 ; i}=Q_{2 j i}
$$

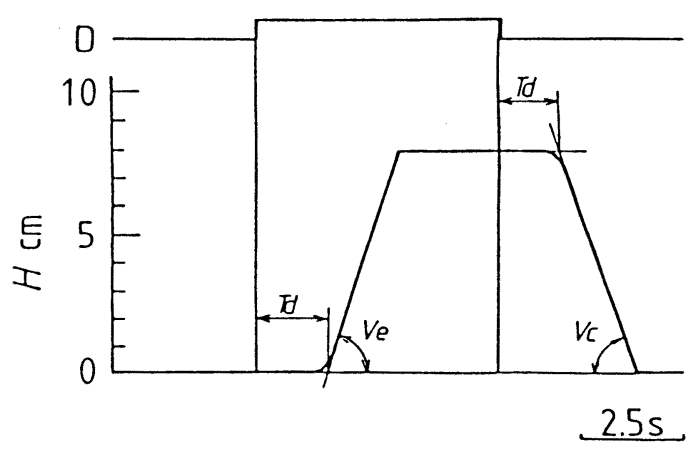

Fig.2 Anesthetic time and moving velocity A.t $t=0, Q_{1 \mathrm{Hi}}=0$ and 
From Eqs. (14), (15), (17) and (18), we have

$$
\begin{aligned}
& P_{H i}=\left(K_{1 L i}{ }^{2} P_{H i}+k_{1 H i}{ }^{2} P_{\theta}\right) /\left(K_{1 L i}{ }^{2}+k_{1 H i^{2}}\right) \\
& P_{L i}{ }^{\prime}=k_{2 H i}{ }^{2} P_{L i} /\left(k_{2 L i}{ }^{2}+k_{2 H i}{ }^{2}\right)
\end{aligned}
$$

and

$P_{H i}=P_{\theta}-A_{H i}{ }^{2} V_{j i}{ }^{2}\left(K_{1 L i}{ }^{2}+K_{1 H i}{ }^{2}\right) / K_{1 L i}{ }^{2} K_{H H i}{ }^{2}$

$P_{L i}=A_{L i}{ }^{2} V_{j i}{ }^{2}\left(K_{2 L i}{ }^{2}+K_{2 H} i^{2}\right) / K_{2 L i}{ }^{2} K_{2 H i}{ }^{2}$

Then the moving velocity $v_{i}$ is represented as

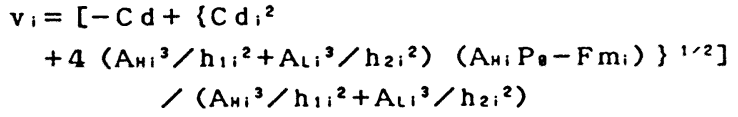

where

$$
h_{k i}=k_{k H i} k_{k L i} /\left(k_{k H i}+k_{k L i}\right)
$$

\section{EXPERIMENTAL EQUIPMENT}

In this paper the digital control system with 4 tandem cylinders and 4 directional control valves controlled by a micro-computer were used. Each of their strokes is 1 to $8 \mathrm{~cm}$, and one end was fixed and the other was free as shown in Fig. 3. The dynamic characteristics of this system was investigated.

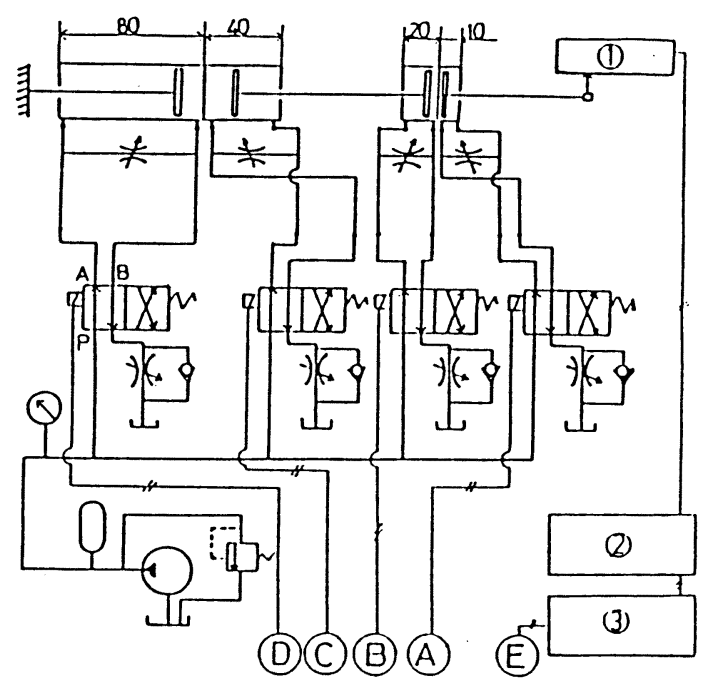

(1) Displacement Transducer (2) Strain Meler (3) Visigraph

Fig.3 Hydraulic circuit
The controlling part was constructed by 280 CPU representing 8 bits microcomputer, 58725 RAM $(2 \mathrm{kB})$ and 8255 PIO as shown in Fig. 4. The program written by 280 assembly language was run after memorized to RAM as machine language. The output against each step of the program was brought through 4 signal lines of $\mathrm{C}$ port in 8255 PIO as ON-OFF signals of TTL revel. So this system could get 16 kind of outputs in TTL revel (0000B-1111B). These 4 lines were connected to magnetic relays (contact rating $A C 100 \mathrm{~V}$ ) which controlled each 4 directional control valves (max. flow rate $18 \mathrm{l} / \mathrm{min}$. ). Thus 4 directional control valves were set $O N$ or $O F F$ independently. And $\mathrm{ON}-\mathrm{OFF}$ switching time was recorded in the electromagnetic oscillograph by the electric signals sent from B port of 8255 PIO.

In the hydraulic driving part shown in Fig. 3, the flow of the mineral oil( ISO viscosity grade $V G 46$, density $0.873 \mathrm{~g} / \mathrm{cm}^{3}$ ) from the variable displacement radial piston pump was separated into 4 directions, going to each directional control valve ( $\max$. flow rate $9.5 \mathrm{l} / \mathrm{min}$. ), hoses ( inner diameter $12.7 \mathrm{~mm}$, outer diameter $26.5 \mathrm{~mm}$, length $3 \mathrm{~m}$, pressure for daily use $2.9 \mathrm{MPa}$ ) and 4 cylinders (one side rod type, inner diameter $25 \mathrm{~mm}$, rod diameter $14 \mathrm{~mm}$, max. pressure $3.4 \mathrm{MPa}$ ). The 4 cylinders were connected in series and on the level, of which the strokes were

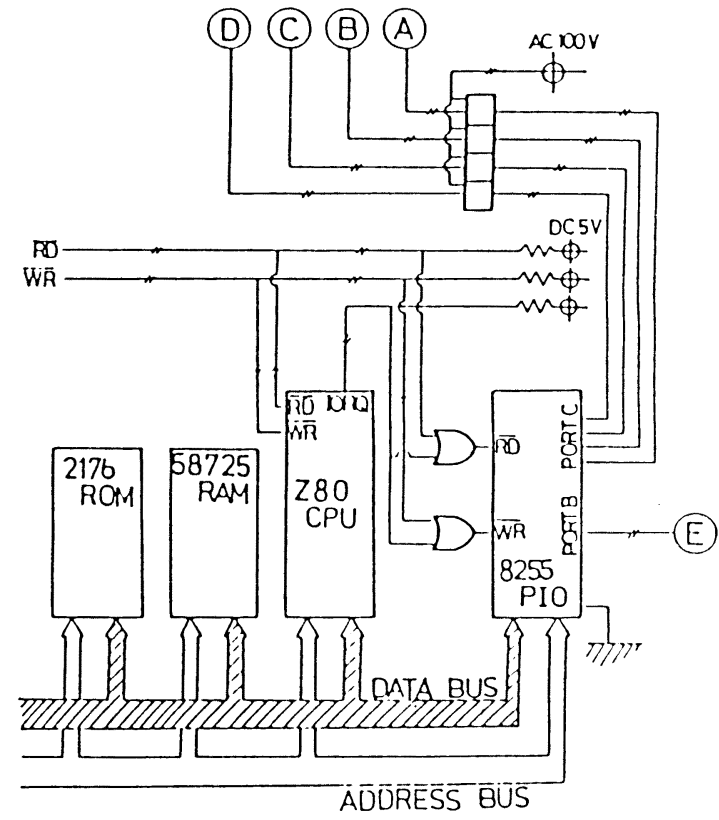

Fig.4 Digital control unit 
8, 4, 2 and $1 \mathrm{~cm}$ in order from the fixed end of the system. The piston in each cylinder was stopped at either end according as directional control valves switching. Therefore this hydraulic system had 16 positions of 0 to $15 \mathrm{~cm}$ at interval of $1 \mathrm{~cm}$. When all cylinders were retarded, the position was 0 , the standard position. The output displacement of the system, the position of the free end, was recorded in the electromagnetic oscillograph as an electrical signal from $B$ port.

As shown in Fig. 5 the bulk modulus of the oil $\mathrm{K}_{0}[=\mathrm{P} /(\delta \mathrm{V} / \mathrm{V})]$ is $1.35 \mathrm{GPa}$, and the apparent bulk modulus of the hose is $\mathrm{K}=25 \mathrm{MPa}$ irrespective of the included oil.

As shown in Fig. $6 \mathrm{k}_{\mathrm{ji}}$ are function of oil temperature. Other coefficients were defined as $\mathrm{Cd}_{i}=1.0 * 10^{3} \mathrm{~kg} / \mathrm{s}, \mathrm{Fm}_{i}=20 \mathrm{~N}$ and $\mathrm{Fs}_{i}=2.0 * 10^{2} \mathrm{~N}$.

\section{EXPERIMENTAL RESULTS AND DISCUSSION}

\section{Characteristics of each cylinder}

The output displacement of each cylinder vs. time was measured by the displacement transducer. As shown in Fig. 2 displacement of the cylinder had the anesthetic time $t d$ before starting, then kept uniform motion, and stopped at the end when the time of ON-OFF signals to a directional control valve was $t_{0}$. The anesthetic time $t d$, about $0.1 \mathrm{~s}$, was much longer than the time of opening or closing the electric valve, $0.01 \mathrm{~s}$. It was caused by the expansion of the hose when the oil started flowing into the hose, smoothing the sudden pressure rise. On the other hand the velocity was suddenly changed from $v=0$

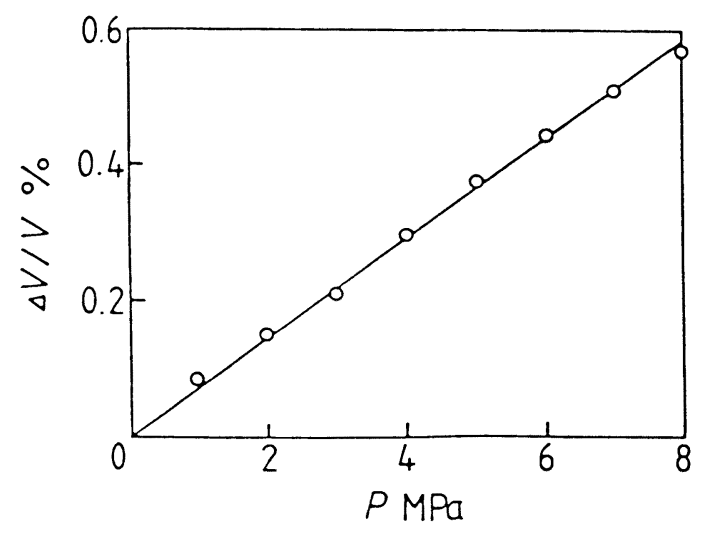

Fig.j Relation between pressure and compressibility to a certain constant one $v=v_{e}$ in very short time compared to the time of $t d$ and of uniform motion. There was no problem also about stickslip and so on at high speed.

Figure 7 shows the relationship

\begin{tabular}{|c|c|c|c|c|}
\hline \multicolumn{4}{|c|}{ Symbol } & \multirow{2}{*}{$\begin{array}{r}\text { Regression } \\
\text { Line }\end{array}$} \\
\hline & & Exi. & Cni. & \\
\hline \multirow{2}{*}{$\begin{array}{l}\text { Direction } \\
\text { Conlrol } \\
\text { Valve }\end{array}$} & Porrp+Cylinder & (y & () & $-\cdots$ \\
\hline & Cylinder tTank & os & $\mathbf{0}$ & - - \\
\hline \multicolumn{2}{|c|}{ Flow Melering Valve } & \multicolumn{2}{|c|}{$\mathrm{O}$} & \\
\hline
\end{tabular}

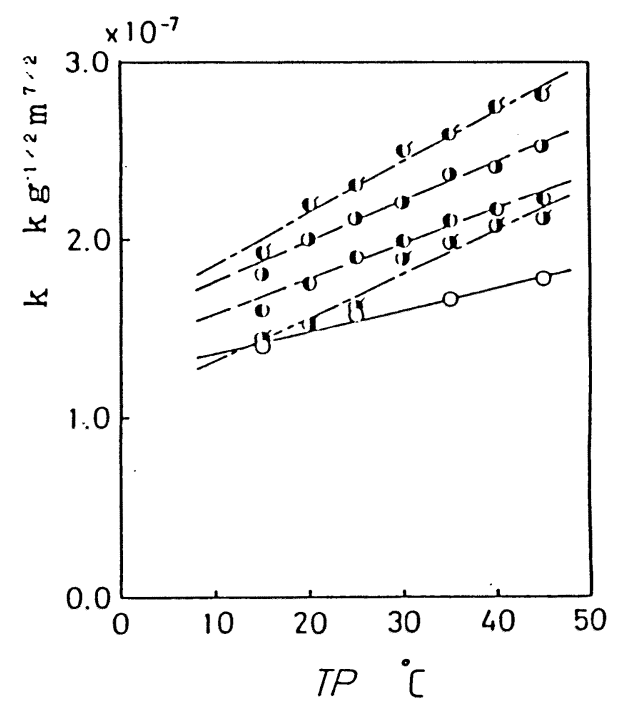

Fig. 6 Coefficient of flow rate between hose and valve

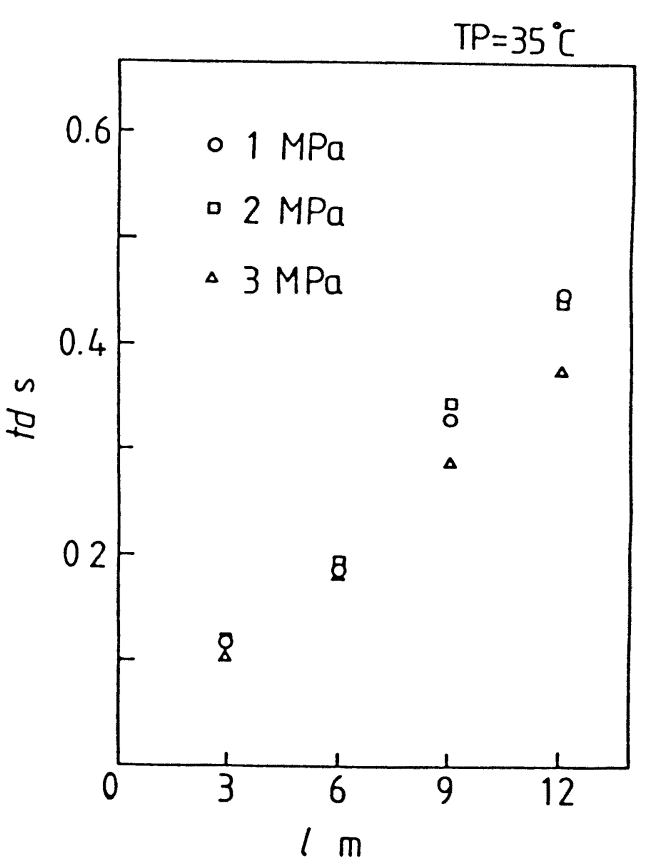

Fig.7 Anesthetic time td 
between the anesthetic time td and the length of the hose 1 . td is in direct proportion to 1 , showing strong influence of the hose. This result agrees with Eq. (14) in which td is directly proportional to 1 . It also suggests that $t d$ is related to the time of expanding the hose enough.

As shown in Fig. 8 td decreases according as the increase in the supply pressure. As $k_{1 H}=k_{2 L}$, and $A_{H}=A_{L}=A$ in $E q$. (14),

$$
\begin{aligned}
& t d_{i i}=T_{i i}\left\{P_{\theta^{1 / 2}}-\left(P_{\theta}-2 F s_{i} / A\right)^{1 / 2}\right\} \\
& \therefore \mathrm{dt}_{\mathrm{ji}} / \mathrm{dP}_{\mathrm{B}} \\
& =T_{j i} / 2\left\{1 / P_{\theta^{1 / 2}}-1 /\left(P_{8}-2 F s / A\right)^{1 / 2}\right\} \\
& <0
\end{aligned}
$$

$$
d^{2} t d_{j i} / d P \theta^{2}>0
$$

Therefore $t d$ is decreasing function of $P_{0}$ and it has small range of change. The larger $P_{0}$ is, the smaller change of $t d$ is.

The relationship between the supply pressure $P_{0}$ and the velocity of the cylinder $v$ is represented as the inclination of the line in Fig.8. It shows that the velocity is increasing when $P_{0}$ is also increasing. This tendency agrees with that of the model Eq.(21). Generally the velocity on the extending side is larger than that on the contracting side because of the difference of the piston area.

Then $k_{1 \mathrm{H}}$ and $\mathrm{k}_{2 \mathrm{~L}}$ are shown in Fig. 6 . Where Ext. and Cnt. reveal on the cylinder extending side and on the its contracting side, respectively.

\section{Characteristics of cylinder system}

The displacement of the whole system is the sum of each cylinder's displacement. When each cylinder can displace independently one another, the simulation of digital hydraulic system is wade to be sum of each cylinder's displacement. Therefore it can be constructed using $v$ and td introduced from the above-mentioned model equations. Suppose each cylinder has an anesthetic time after the signal sent from a micro-computer at first, then keeps uniform motion with velocity $\mathrm{v}$, and stops when it extends or contracts enough. We need not take care about interdependence between each cylinders -..- the difference of each cylinder's force, the pressure decrease by feeding other cylinders, which can be eliminated by increasing the capacity of a pump.

The simulation and the experimental result of output displacements vs. time were compared.

The parameters $k_{k j}, C d, F m$ and $F s$ were calculated by the following way: $k_{k j}$ was given by Fig. 6 as the function of the oil temperature. Cd, Fm and Fs were calculated from $v$ and $t d$ as average values $c d=1.0 * 10^{3}$ $\mathrm{kg} / \mathrm{s}, F \mathrm{~m}=20 \mathrm{~N}$ and $\mathrm{Fs}=2.0 * 10^{2} \mathrm{~N}$.

As shown in Fig. 9 when the output displacement of the system was changed from 8 to $7 \mathrm{~cm}$ ( $1000 \mathrm{~B}$ to 0111B), it has a projecting part on the graph vs. time,
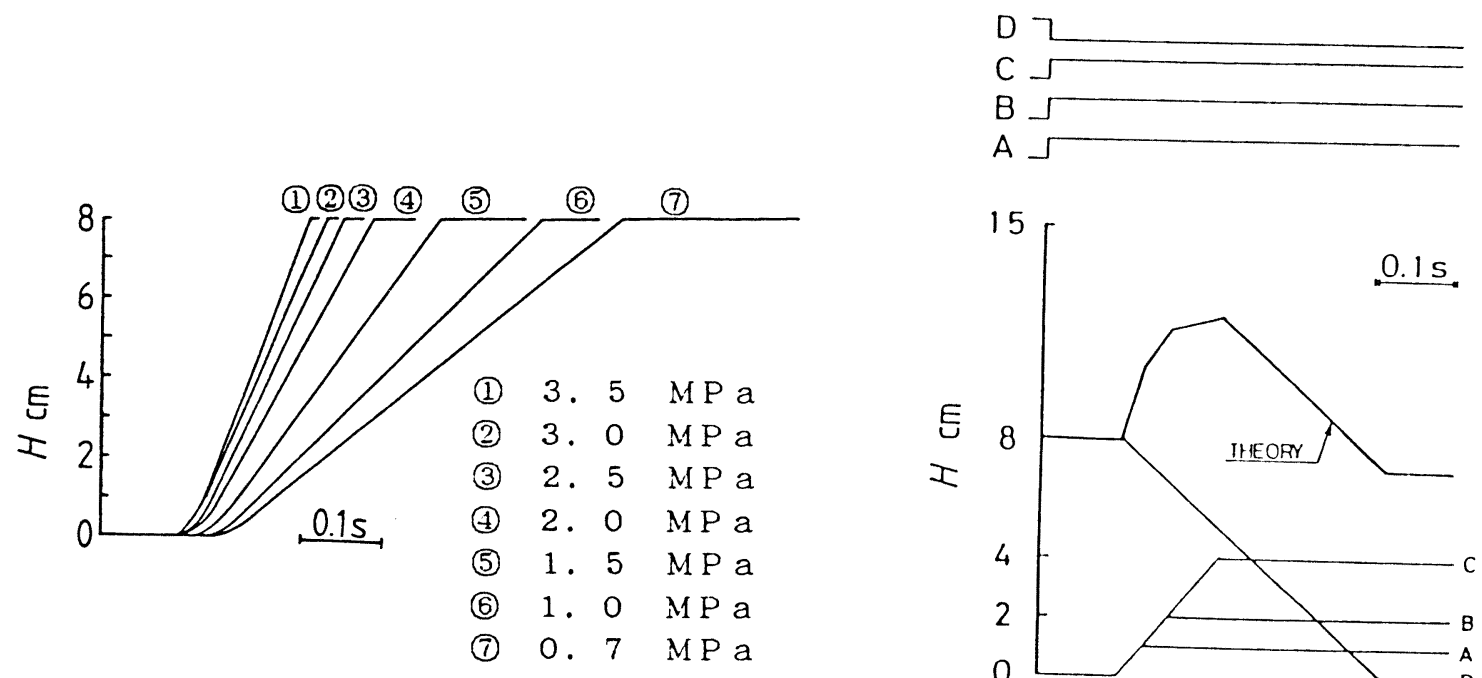

Fig.8 Characteristics of one cylinder

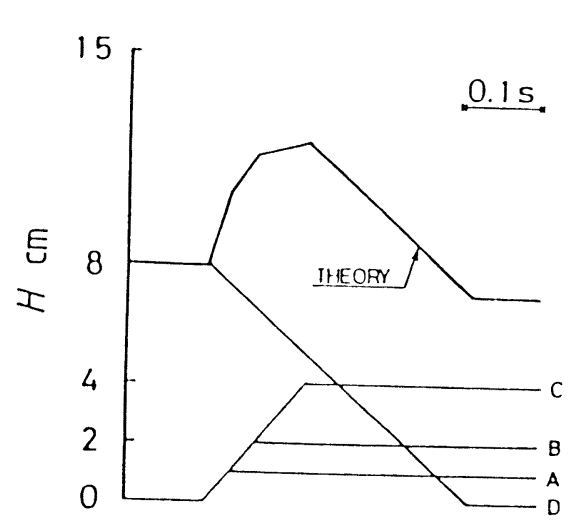

Fig.9 Output displacement of multi-cylinder system 
which is different from the digital signal of micro computer. This is because the cylinders with the strokes 1,2 and $4 \mathrm{~cm}$ are driving when the cylinder with the stroke $8 \mathrm{~cm}$ doesn't reach to the end yet. Such a projecting part is revealed when displacement is changed from 3 to $4 \mathrm{~cm}$ ( CO11B to 0100B ) or from 11 to $12 \mathrm{~cm}(1011 \mathrm{~B}$ to $1100 B$ ) etc..

Figures 10-12 are comparisons of the experimental results and the simulation. A fine line is the experimental result, a heavy line is the simulation and a dotted line is the purpose function. A,B,C and D is the ON-OFF signal sent to $1,2,4$ and

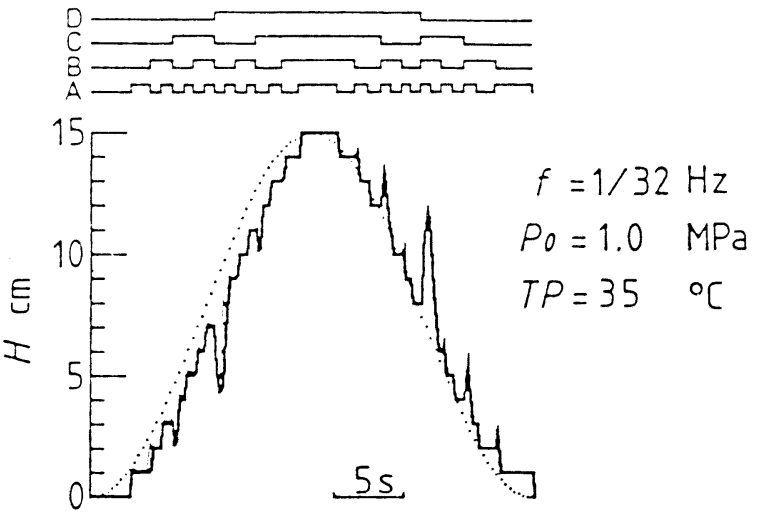

Fig.10 Experimental result and siqulation of system

$\left(\mathrm{P}_{8}=1.0 \mathrm{MPa}\right)$

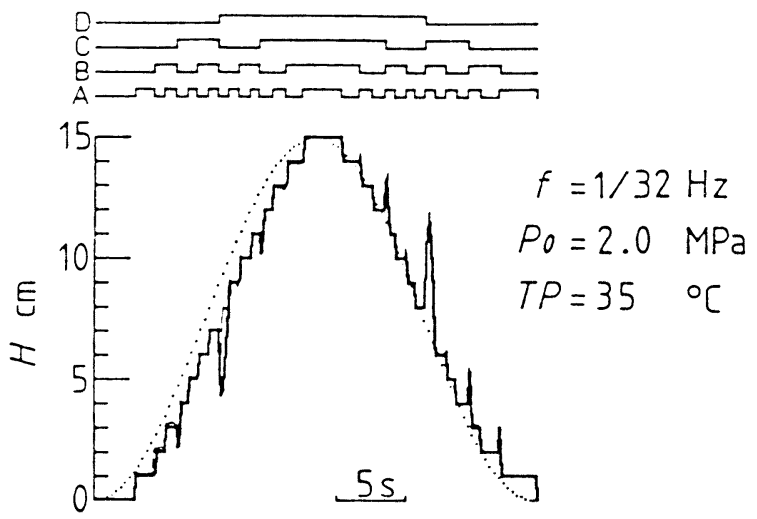

Fig.11 Experimental result and simulation of system

$\left(\mathrm{P}_{8}=2.0 .4 \mathrm{~Pa}\right)$
$8 \mathrm{~cm}$ cylinder, respectively. In this case the purpose function was given as a sin curve, and we didn't intend to close the experimental result to it but to the digital signal from micro-computer. Practically we can get a smooth curve by adjusting the switching time.[5] The purpose of this study was to agree the experimental result and the simulation.

Figures 10, 11 and 12 show the cases of the supply pressure $P_{0}=1.0,2.0$ and $3.0 \mathrm{MPa}$ at the oil temperature $\mathrm{TP}=35^{\circ} \mathrm{C}$ and the frequency of the purpose function $f=1 / 32 \mathrm{~Hz}$. The width of the projecting part on the graph became narrower and it became

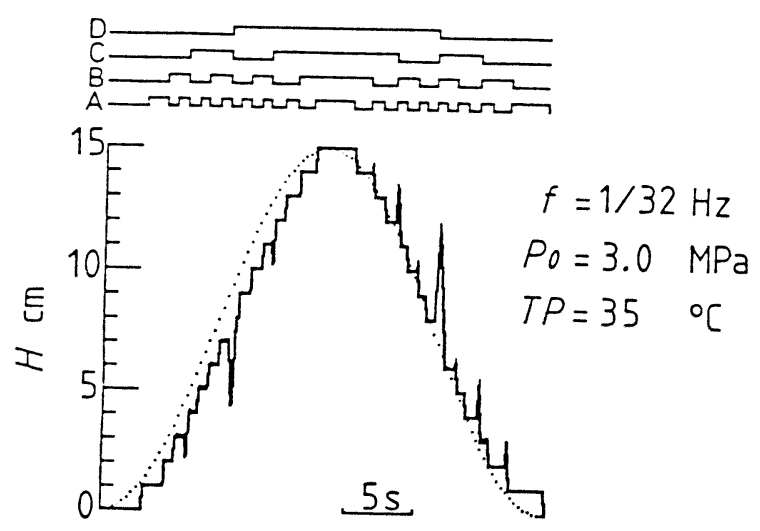

Fig.12 Experimental result and simulation of system

$\left(\mathrm{P}_{0}=3.0 \mathrm{MPa}\right)$

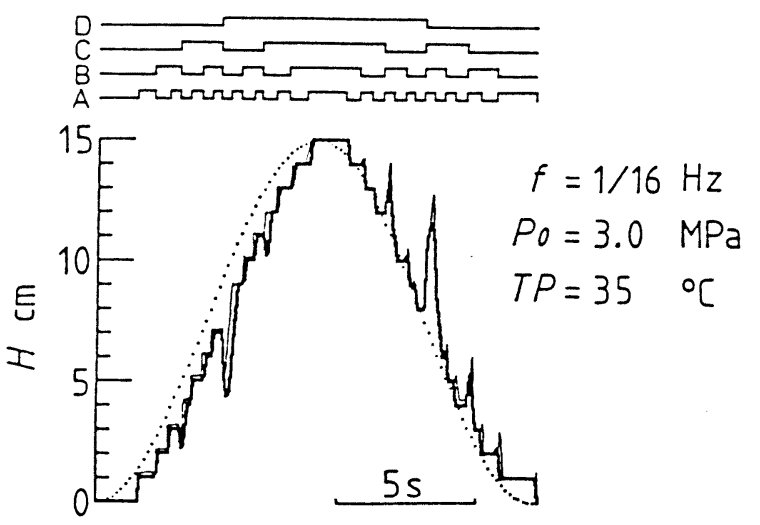

Fig.13 Experimental result and simulation of system $\left(f=1 / 16 \mathrm{~Hz} \quad \mathrm{P}_{\theta}=3.0 \mathrm{MPa}\right)$ 
204

an acute angle. We can see that tendency on the simulation, too. It depends on the velocity of the piston, increasing in proportion to the increase in the pressure. The simulation forecast well where the projecting part is, but it tends to have a shorter peak. One of the reasons is the friction between displacement transducer and the connecting part of cylinders' output part as the piston is extending or contracting, and next one is the inertia caused by sudden change in the direction. And the step condition reveals clearer at the higher pressure for the increase in moving velocity $v$ and the decrease in anesthetic time td. The length of the anesthetic time is same at every cylinder, which makes some changes in only one step condition. But it influences a whole shape when the next signal is sent during the anesthetic time.

Figure 13 is the case of $\mathrm{TP}=35^{\circ} \mathrm{C}$, $P_{0}=3.0 \mathrm{MPa}$ and $f=1 / 16 \mathrm{~Hz}$. The projecting part stands out highly compared to $f=1 / 32$ $\mathrm{Hz}$. There is no step condition appointed in the displacement $7-8 \mathrm{~cm}$ and $12-13 \mathrm{~cm}$. It would depend on that the next switching action is beginning, before the cylinder has never extended or contracted completely according to the switching at close intervals. The simulation also has such tendency.

\section{CONCLUSIONS}

In this research, the dynamic characteristics of a digital hydraulic system controlled by a micro-computer and consist of the four cylinders, the strokes of which were $1,2,4 \mathrm{~cm}$ and $8 \mathrm{~cm}$, connected in series was investigated experimentally and theoretically. The results confirmed in this research are as follows.

(1) The system objected in this research is useful when the speed of positioning is not too fast.

(2) In some cases, the outputs of the system objected in this research show some unexpected motions as overrunning transiently but finally arrive at the tar- get positions of the systen during the positioning.

(3) The contrivances of the software to control the micro-computer can make the unexpected motion of the system much smaller.

\section{ACKNOWLEDGMENT}

The authors heartily appreciate Mr. Kiyoshi Kitaura and his co-workers in Taiyo TekkoK.K. to their assistance for developing the experimental apparatus used in this research.

\section{POSTSCRIPT}

Today, automatic systems are driven and controlled usually by electrical devices. But special control systems will be needed under some exceptional conditions, such as in strong magnetic fields or in explosive gases. If someone use the system objected in this research with long flexible hoses, he may completely get rid of the bad influences of the strong magnetic fields and the dangers of explosion. Therefore, this research is useful for the development not only of the computer-controlled hydraulic systems but also of the systems used in such special environments.

\section{REFERENCES}

[1] Tanaka,H. and Nakano,T., Preprint of Spring Symposium on Hydraulics and Pneumatics, (1986), 21. (in Japanese)

[2] Ota,s. et.al., Jour. of J.H.P.S., 103 (1979), 12. (in Japanese)

[3] Tanaka,H., ibid., 16-1(1985), 3. (in Japanese)

[4] Nakano,K. et.al., ibid., 6-3 (1970), 201. (in Japanese)

[5] Uenishi,M. et.al., Preprint of Spring Symposium on Hydraulics and Pneumatics, (1985),9. (in Japanese) 